\title{
ANÁLISE DO RISCO DA OCORRÊNCIA DE BIOTIPOS DE PLANTAS DANINHAS RESISTENTES AOS HERBICIDAS ${ }^{1}$
}

\author{
RIBAS A. VIDAL ${ }^{2}$ e NILSON C. FLECK $^{2}$
}

RESUMO

\begin{abstract}
A análise do risco da ocorrência de biotipos de plantas daninhas resistentes aos herbicidas dispõe de fundamentos te óricos adequados, porém é limitada pela falta de mais informações genéticas das espécies daninhas. O risco de encontrar uma área infestada com biotipos de plantas daninhas resistentes aos herbicidas de pende de do is aspectos: da probabilidade de seleção de um mutante resistente a ce rto mecanismo de ação herbicida; e da probabilidade de infestação da área com plantas resistentes, a partir daquele mutante selecionado. $\mathrm{O}$ objetivo deste trabalho foi estudar a influência de fatores genéticos na probabilidade de seleção de um mutante resistente a determinado mecanis mo de ação herbicida e assim prever o risco de serem encontrados biotipos de plantas daninhas resistentes aos herbicidas. Os fatores que determinam a probabilidade de selecionar um mutante resistente aos herbicidas podem ser
\end{abstract}

agrupados em três categorias: os relacionados à genética da resistência; os relacionados ao número de plantas daninhas sob seleção; e os relacionados ao herbicida. Os fatores relacionados à genética da resistência são dependentes da freqüência inicial do alelo de resistência, da dominância e do tipo de polinização da espécie. Os fatores relacionados ao número de indivíduos são a área tratada com o herbicida e o grau de infestação da área. Os fatores relacionados aos herbicidas são o seu mecanismo de ação e a sua frequiência de uso na área. As previsões matemáticas indicam alto risco de ocorrência de resistência em áreas com alta inf estação de plantas daninhas e que são aspergidas com herbicidas cujos mecanismos de ação apresentam histórico de al ta frequiên cia inicial do alelo de resistência nas populações de plantas daninhas.

Palavras chave: Resistência, simulação, previsão, genética.

\section{ABSTRACT \\ The risk of finding herbicide resistant weed biotypes.}

The prediction of occurrence of weed resistance to herbicides is limited by the scarcity of information on weed genetics. The risk of finding a resistant weed biotype depends on two aspects: the probability of selecting a herbicide resistant mutant, and the probability of spreading the resistance in the area. The objectives of this work were to study factors that control the probability of selecting a herbicide resistant mutant, and to predict the risk of selecting a resistant plant. The factors that control the probability of selecting a herbicide resistant mutant are grouped in three categories: those related to the genetics of resistance, those related to the number of plants under selection, and those related to the herbicide. The genetics of resistance is governed by the initial frequency of the resistant allele, dominance of the gene, and

1Recebido para publicação em 09/12/96 e na forma revisada em 15/10/97. Trabalho apresentado no SIMPÓSIO SOBRE MANEJO DA RESISTÊNCIA DE PLANTAS DANINHAS AOS HERBICIDAS. em 12/11/96, em Jaboticabal-SP. 2 2Eng. Agr., Ph. D., Professores do 2Departamento de Plantas de Lavoura. Faculdade de Agronomia, Universidade Federal do Rio Grande do Sul, Caixa Postal 776, CEP 90001-970 Porto Alegre, RS, Brasil. Email: vidal@fl.if.ufrgs.br. 
type of species pollination. The number of plants under selection depend on size of the herbicide treated area and weed density. The factors related to the herbicide are its mechanism of action, and frequency of use of the same mechanism of action in the area. Computer simulations indicate great risk of occurrence of a resistant mutant in areas

\section{INTRODUÇÃO}

Em ge ral. as análises de risco são previsões que, para serem precisas, dependem de fundamentos teóricos sólidos e de informações históricas com descrições detalhadas para serem utilizad as nos modelos teóricos disponíveis. A análise de risco da ocorrência de plantas daninhas resistentes aos herbicidas dispõe de fundamentos teóricos adequados de genética de populações. Contudo, ao nível mu ndial, as informações históricas de casos de resistência limitam-se a descrever, caracterizar e quantificar o fenómeno da resistência, mas fornecem poucas informações genéticas que possam ser utilizadas nos modelos teóricos exi stentes (Da rmency, 1994). Desta forma, a análise do risco da oc or rência de resistência é bastante limitada, tornando-se praticamente impossível predizer com segurança a ocorrência destas plantas resistentes nas áreas agrícolas (Anônimo, 1995).

$\mathrm{O}$ risco de encontrar uma área infestada com plantas daninhas resistentes aos herbicidas depende de dois aspectos: da probabilidade de se leção de um mutante resistente a certo mecanismo de ação herbicida; e da probabilidade de infestação da área com plantas resistentes, a partir daquele mutante selecionado. $\mathrm{O}$ segundo aspecto foi extensivamente explorado por diversos autores (Gressel \& Segel, 1978; Gressel \& Segel, 1990; Putwain \& Mortimer, 1989; Maxwell et al. 1990 ; Jasieniuk et al. 1996), enquanto poucos autores se detiveram em abordar o primeiro with high weed density, mainly those sprayed with herbicides whose mechanisms of action present history of high initial frequency of the resistant trait on the weed populations.

Key words: Resistance, simulation, prediction, genetics.

aspecto.

Os fatores que determinam a probabilidade de se encontrar um mutante resistente aos herbicidas com determinado mecanismo de ação, podem ser agrupados em três categ orias: os relacionad os à ge nética da resistência; ao número de plantas daninhas sob seleção e ao herbicida.

$\mathrm{O}$ principal fator relacionado à genética da resistência e, provavelmente, o mais importante fator de risco de ocorrência de plantas daninhas resistentes aos herbicidas, é a freqüência inicial do alelo de resistência. Variabilidade genética para resistência é um fator indispensável numa espécie susce tível para que seja possível haver evolução de biotipos resistentes ao herbicida. A resistência não é induzida pelos herbicidas (Holt et al. 1993) mas ocorre naturalme nte devido a sel eção de indivíduos em populações com variabilidade genética.

Na Tabela 1, adaptada por Vidal (1997) a partir da literatura internacional, verifica-se que só há estimativas sobre a freqüência inicial do alelo de resistência para os herbicidas inibidores de acetolactato sintase (ALS) e para os inibidores do fotossistema 2 (FS2). A freqüência do alelo de resistência para os inibidores de ALS é semelhante à frequiência de mutações espontâneas, que ocorrem a aproximadamente $10^{-6}$ gametas por locus por geração (Merrell, 1981). A freqüência do alelo de resistência para os inibidores do FS2 varia entre $10^{-9}$ e $10^{.12}$, sendo portanto evento mais raro do que a dos inibidores de ALS. 
TAB ELA 1. Número de espécies resistentes e freqüência inicial do ale lo de resistência (R) para herbicidas de diversos mecanismos de ação, encontrados na literatura internacional.

\begin{tabular}{lcc}
\hline \multicolumn{1}{c}{$\begin{array}{c}\text { Mecanismos de ação dos } \\
\text { herbicidas }\end{array}$} & $\begin{array}{c}\text { Número de espécies com } \\
\text { biotipos resistentes }\end{array}$ & $\begin{array}{c}\text { Freqüência inicial do alelo } \\
\text { resistente }\end{array}$ \\
\hline Inibidores da ACCase ${ }^{1}$ & 10 & $?$ \\
Inibidores da ALS & 17 & $10^{-6}$ \\
Hormonais & 8 & $?$ \\
Inibidores do FSI & 16 & $?$ \\
Inibidores do FS2 & 67 & $10^{-9}$ a $10^{-12}$ \\
Inibidores da tubulina & 5 & $?$ \\
\hline & & \\
Adaptado de Vidal. 1997. & & \\
ICCase = acetil coenzima A carboxilase, Al.S = acetolactato sintase, FS1 = fotossistema I. FS2 = fossistema II \\
Informaçס̃es nåo disponiveis na literatura.
\end{tabular}

A Tabela 1 sugere, ainda, que determinados mecanismos de ação herbicida possuem maior frequiência inicial do alelo de resistência, ap resent an do maior risco de ocorrência de plantas daninhas resistentes ao produto. Divers os mecani smos de ação de herbicidas não estão listados na Tabela 1 porque não há registros específicos da ocorrência de plantas resistentes a estes compostos. Contudo, pode até haver casos de resistência múltipla, como por exemplo os he rbicidas inibidores de enolpir uvil chiquimato fosfato sintase (EPSPs) e do crescimento da parte aérea de plântulas (Vidal, 1997). Já compostos de mecanismos de ação tais como os inibidores de protoporfirinogen oxidase (PROTOX) e inibidores da formação de carotenóides não apresentam registros de espécies resistentes (Vidal, 1997). Provavelmente, as espécies vegetais apresentem baixa freqüên cia inicial de resistência para herbicidas com tais mecanismos de ação, ou a área tratada com estes herbicidas não é suficientemente grande para a ocorrência de resistência.

Outro fator relacionado à genética da resistência é a dominância do gene envolvido na resistência. Evoluções adaptativas tais como resistência aos inseticidas, melanismo industrial ou to le rância aos me ta is pe sados, parecem favorecer genes dominantes ou parcialmente dominantes (Macnair \& Cumbes, 1989; Jasieniuk et al., 1996). Na Tabela 2 demonstra-se que a resistência aos herbicidas para a maioria dos mecanismos de ação também é determinada por genes dominantes ou semi-dominantes. Muitos cientistas alegam que a evolução adaptativa requer um ganho de função, devendo ser governad o por um gene dominante. Contudo, uma explicação mecanística para este fenômeno está relacionada aos aspectos genéticos da espécie. O mutante com alelo de resistência dominante apresenta condições de deixar como descendentes indivíduos resistentes, independente do tipo de fecundação da espécie.

Quando o alelo resistente for recessivo (d) e o alelo suscetível for dominante (D), o mutante resis tente ocorrerá na forma heterozigota (Dd) e será eliminado com a aplicação do herbicida. Caso este organismo escape do tratame nto herbicida (por efeito do ambiente, ou efeito guarda-chuva, ou germinação posterior à aplicação) e a espécie for de polinização cruzada, ele irá cruzar com plantas não mutantes, homozigotas e suscetíveis (DD), produzindo apenas descendentes suscetíveis (50\% DD e 50\% Dd). Assim, o alelo resistente 
recessivo somente mostra rá cond ições de perpetuar-se caso a espécie vegetal seja autógama, pois $25 \%$ dos descendentes serão resistentes (dd). Na Tabela 2, observa-se que uma es pécie resistente aos inibidores de polimerização de tubulina é recessiva e, de fato, a espécie apresenta autofecundação. Nos demais casos apresentados na Tabela 2, constata-se a ocorrência de gene dominante ou se mi-dominante em es pécies au tó gamas ou alógamas. Ressal ta-se que na maioria das espécies resistentes aos inibidores de fotossistema 2, a resistência se deve à mutação presente em gene cloroplasmático e não envolve re combin ação gênica, mas envolve herança maternal apenas (Vidal, 1997).

TABELA 2. Tipo de polini zação da espécie resistente e dominância do ale lo de resistência para herbicidas de diversos mecanismos de ação.

\begin{tabular}{|c|c|c|}
\hline $\begin{array}{l}\text { Mecanismos de ação dos } \\
\text { herbicidas }\end{array}$ & Tipo de polinização & Dominância do alelo \\
\hline Inibidores da ACCase ${ }^{I}$ & autógama, alógama & $\mathrm{SD}^{2}$ \\
\hline Inibidores da ALS & autógama, alógama & $\mathrm{D}, \mathrm{SD}$ \\
\hline Hormonais & alógama & $\mathrm{D}$ \\
\hline Inibidores do FS1 & autógama, alógama & $\mathrm{D}, \mathrm{SD}$ \\
\hline Inibidores do FS2 & autógama, alógama & Maternal $^{3}(\mathrm{SD})^{4}$ \\
\hline Inibidores da tubulina & autógama & $r$ \\
\hline
\end{tabular}

A probabilidade de se encontrar um mutante resistente aos herbicidas aumenta com o incremento no número de plantas de uma espécie aspergidas com determinado herbicida. Assim, haverá mai or probabilidade de ocorrência de resistência em três situações: a) numa área altamente infestada com uma espécie, b) numa espécie de planta daninha que infeste uma grande área, ou c) em ambas situações, simultaneamente. Al ta intensidade de uso de herbicidas de determinado mecanismo de ação, ou a utilização de herbicidas com longo efeito residual, implicam em maior número de plantas expostas ao(s) composto(s), aumentando a probabilidade de se selecionar um mutante resistente ao produto.

O objetivo deste trabalho foi estudar a influência de fatores que contribuem para a seleção de um mutante resistente a herbicidas de determinado mecanismo de ação e assim prever o risco de serem encontrados biotipos de plantas daninhas resistentes aos herbicidas.

\section{MATERIAIS E MÉTODOS}

Conforme foi abordado na introdução deste trabalho, ainda faltam muitas informações sobre a genética da resistência. Assim, realizaramse simulações matemáticas utilizando -se as se guintes pre ssuposições: a área tratada pelo herbicida apresenta dimensão de 10 hectares, a espécie vegetal em questão é diplóide, o alelo de resistência é dominante e nuclear (o que implica na possibilidade de oc or rência de recombinações genéticas), a espécie apresenta 
uma geração anual, as aplicações herbicidas são anuais e usam-se produtos de um único mecanismo de ação.

Utilizaram-se equações sugeridas por Me rrell (1981) e Jasieniuk et al. (1996) e apresentadas a seguir para avaliar o risco de ocorrência de um mutante resistente. Considerando-se as pressuposições apresentadas acima quanto às características genéticas do veg etal, no caso de espécies com polinização cruzada a frequência es perada de plantas resistentes (f) é determinada pela equação 1 :

$$
f=p^{2}+2 p q
$$

onde $\mathrm{p}$ representa a frequencia de alelos resistentes na população e q representa a frequencia de alelos suscetíveis na população. No caso de espécies alógamas com $95 \%$ de autofecundação, ou seja com coeficiente de en do ga mi a de aproximadamente $90 \%$, f é determinada pela equação 2 :

$$
f=p^{2}(1-0,9)+2 p q(1-0,9)+p 0,9
$$

A probabilidade de se encontrar um indi víduo resistente numa população de plantas com determinado número de indivíduos (x) é determinada pela equação 3 :

$P=1-(1-f)^{x}$

Para realizar as simulações deste trabalho consideram-se, ainda, situações hipotéticas que abrangessem dois cenários: a) situação onde a frequiência inicial do alelo de resistên cia é $10^{-6}$; e b) situação onde a freqüência inicial do alelo de resistência é $10^{-9}$. Para as simulações previstas no primeiro cenário, onde o ale lo de resistência é muito freqüente, fez-se previsões considerando que a área apresenta infestação anual com densidades constante de 1,5 ou 10 plantas $/ \mathrm{m}^{2}$, por até 4 anos. Para as simulações abrangidas no segundo cenário, onde se avalia uma situação onde o alelo de resistência é mais raro, fez-se previsões considerando que a área apresenta infestação anual com densidades constantes de 50, 100 ou 1000 plantas $/ \mathrm{m}^{2}$, por até 9 anos. Em todas as si mulações descritas acima, avaliou-se a probabilidade de ocorrência de uma planta mutante em espécie apresentando polinização cruzada e também em espécie com $95 \%$ de autofecundação.

\section{RESULTADOS E DISCUSSÃO}

Na Figura 1 apresenta-se a probabilidade de, nu ma es pécie de poli ni zação cruzada, encontrar-se um mutante resistente na situação em que a freqüência inicial do alelo de resistência é $10^{-6}$ para infestações de 1,5 e 10 plantas $/ \mathrm{m}^{2}$ e as aplicações herbicidas são efetuadas de 1 a 4 anos. A probabilidade da ocorrência de um mutante resistente ao herbicida é relativamente baixa (-20\%) com a menor densidade de plantas na área por ocasião da primeira aplicação do produto, mas se acentua quase linearmente com a intensificação de uso do herbicida. Para a maior densidade de plantas ocorre alta probabilidade $(>80 \%)$ de selecionar-se um mutante resistente já por ocasião da primeira aplicação do he rbicida. Nesta densidade de plantas, já a partir do segundo ano, é al tamente provável (100\%) encontrar-se um mutante resistente ao herbicida. 


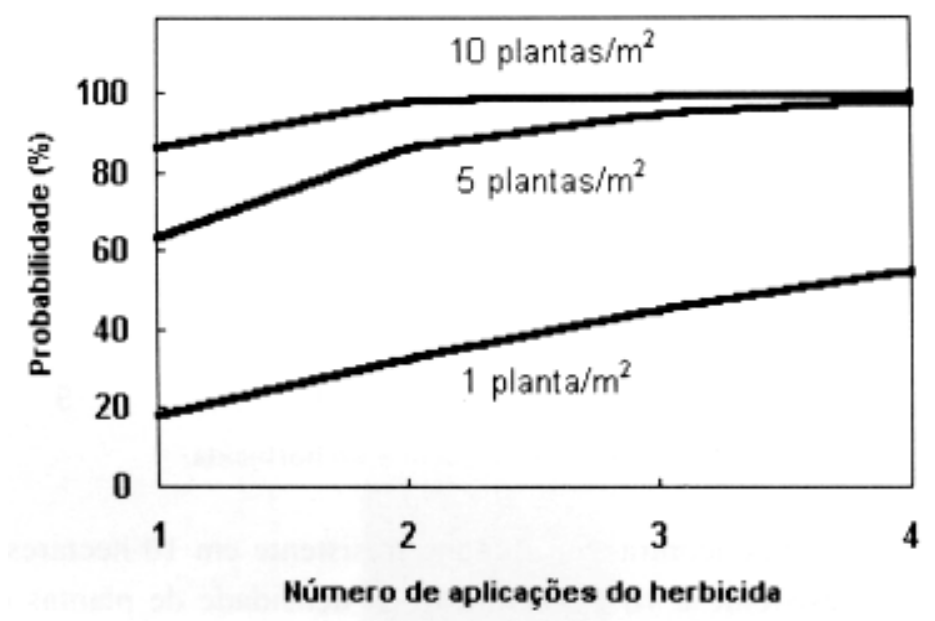

FIGURA 1. Probabilidade (\%) de encontrar um mutante resistente em 10 hectares quando a freqüência inicial do alelo resistente é $10^{-6}$, em função da densidade de plantas e do número de anos com aplicações do herbicida. (Pressuposições: espécie diplóide, ale lo de resistência dominante e nuclear, polinização cruzada e uma geração por ano.)

Na Figura 2 apresenta-se a probabilidade de, nu ma es pécie de polini zação cruzada, encontrar-se um mutante resistente quando a freqüência inicial do alelo de resistência é 10-9 para infestações de 50, 100 e 1000 plantas $/ \mathrm{m}^{2}$ e as aplicações herbicidas perdurarem por 1 a 9 anos. Para as menores densidades de plantas, a probabilidade de encontrar-se um mutante resistente é baixa (<10\%), mesmo após 9 anos de aplicações de herbicidas com o mesmo mecanismo de ação. Para a maior densidade de plantas, a probabilidade de encontrar-se um mutante resistente é relativamente baixa $(-20 \%)$ por ocasião da primeira aplicação do produto e acentua-se até $80 \%$ quando se efetuam aplicações continuadas do mesmo herbicida por até 9 anos.

$$
\text { As simulações das Figuras } 1 \text { e } 2
$$
pressupunham alelo de resistência dominante. Contudo, quand o o gene é recessivo e a espécie for de polinização cruzada, a probabilidade de se encontrar um mutante resistente é zero para todas as situações testadas (densidades de plantas e número de anos de utilização do herbicida). Isto ocorre, porque, numa espécie de polinização cruzada, o mutante com alelo de resistência recessivo (heterozigoto) e seus descendentes, não sobrevivem a pressão de seleção do herbicida, conforme abordado na introdução deste trabalho. 


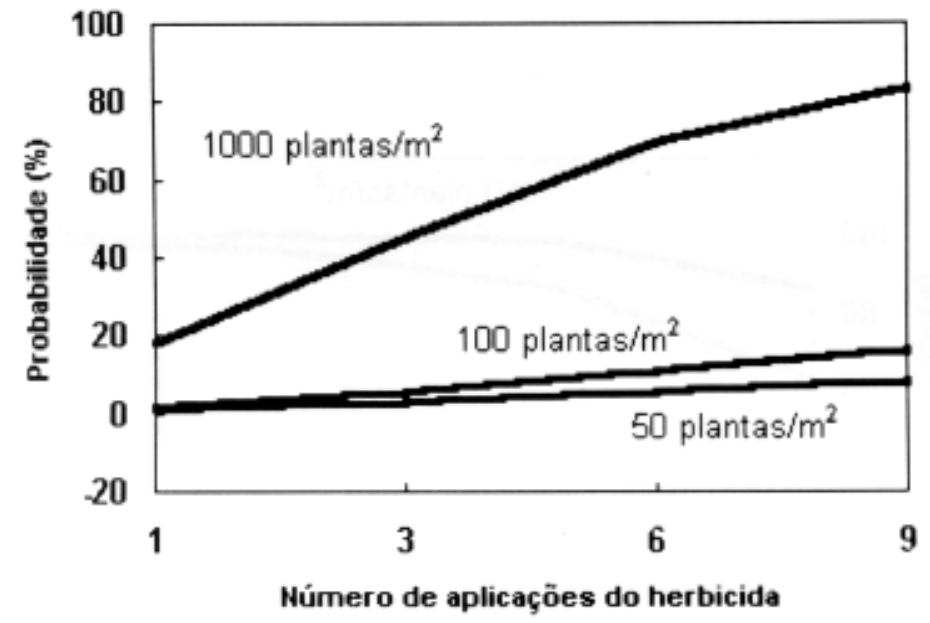

FIGURA 2. Probabilidade (\%) de encontrar um mutante resistente em 10 hectares quando a frequiência inicial do alelo resistente é $10^{-9}$, em função da densidade de plantas e do número de anos com aplicações do herbicida. (Press uposições: espécie diplóide, ale lo de res istência dominante e nuclear, polinização cruzada e uma geração por ano.)

Na Figura 3 apresenta-se a probabilidade de, numa espécie com $95 \%$ de autofecundação, encontrar-se um mutante resistente quando a freqüência inicial do alelo de resistência é 10-6 para infestações de 1,5 e $10 \mathrm{plantas} / \mathrm{m} 2$ e as aplicações herbicidas forem efetuadas por 1 a 4 anos. No primeiro ano de utilização do herbicida, a probabilidade de encontrar-se mutante resistente é 10 a $20 \%$ inferior àque la constata da nas simulações apresentadas na Figura 1, para todas as densidades de plantas, indicando que o aparecimento de mutantes resistentes é maior em espécies com polinização cruzada. A probabilidade de encontrar-se um mutante resistente só atinge $100 \%$ na maior densidade de plantas e por ocasião do quarto ano de utilização do herbicida.

$\mathrm{Na}$ Figura 4 apresenta-se a probabilidade de, numa espécie corn $95 \%$ de autofecundação, encontrar-se um mutante resistente quando a freqüência inicial do alelo de resistência é $10^{-9}$ para infestações de 50, 100 e 1000 plantas/m' e as aplic ações herbicidas variam de 1 a 9 anos. Para as menores densidades de plantas, a probabilidade de encontrar-se um mutante resistente é bai xa (<10\%), mes mo após 9 anos de aplicações de herbicidas que apresentem mesmo mecanismo de ação. Para a maior densidade de plantas, a probabilidade de encontrar-se um mutante resistente também é baixa (-10\%) por ocasião da primeira aplic ação do herbicida, mas se acentua até $60 \%$ quando se efetuam aplicações continuadas do mesmo herbicida por até 9 anos.

As simulações das Figuras 3 e 4 pressupunham alelo de resistência dominante. No en tanto, quando o al elo de resistência for recessivo e a espécie apresentar $95 \%$ de autof ecundação, a probabilidade de se encontrar um mutante resistente é muito similar ao indicado nas Figuras 3 e 4 para todas as situações testadas. 


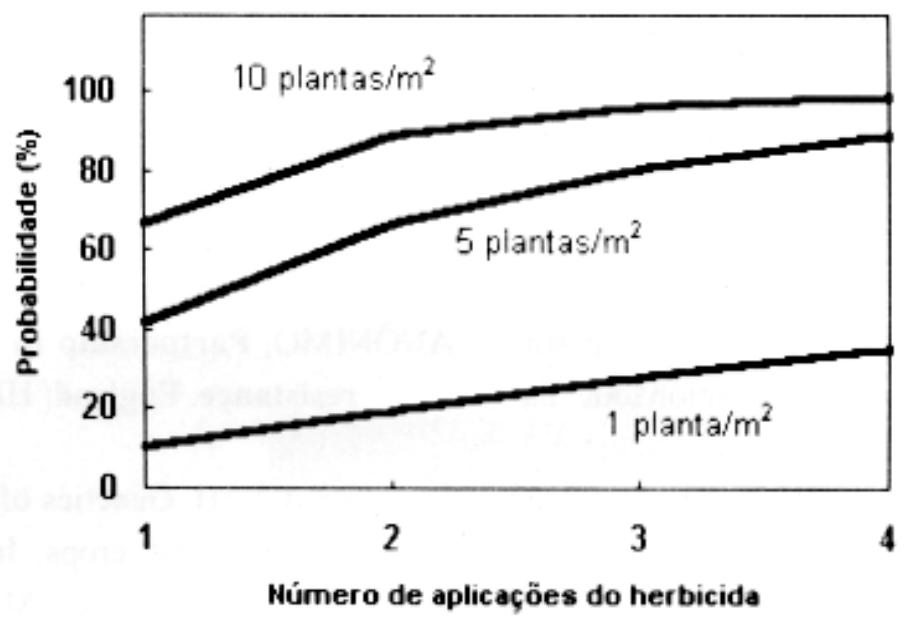

FIG URA 3. Probabilidade (00) de encontrar um mutante resistente em 10 hectares quando a freqüência inicial do alelo resistente é I0-6, em função da densidade de plantas e do número de anos com aplicações do herbicida. ( Pressuposições: es pécie diplóide, alelo de resistência dominante e nuclear, 95\% de autofecundação e uma geração por ano.)

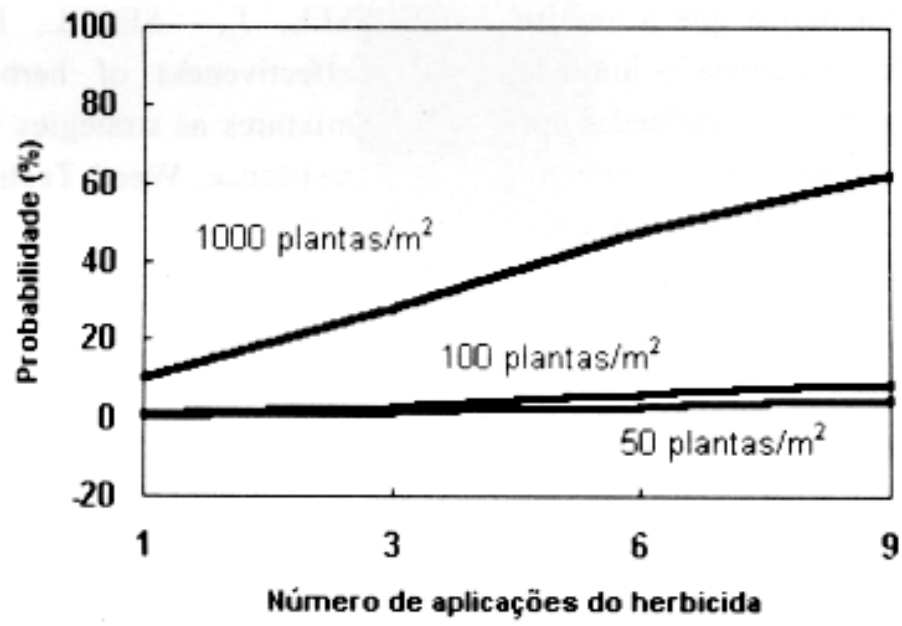

FIGURA 4. Probabilidade (\%) de encontrar um mutante resistente em 10 hectares quando a frequiência inicial do alelo resistente é $10^{-9}$, em função da densidade de plantas e do número de anos com aplicações do herbicida. (Pressuposições: es pécie di plóide, al elo de resistência dominante e nuclear, $95 \%$ de autofecundação e uma geração por ano). 
A discussão apresentada neste trabalho se refe re à probabilidade de se encontrar um indivíduo resistente numa população de plantas daninhas suscetíveis a determinado herbicida. A nível prático, a probabilidade de se detectar a resistência numa área de pende dos fatores mencionados e já discutidos, aliada à probabilidade de infestação da área a partir daquele indivíduo resistente selecionado na população. Diversos trabalhos na li te ratura (Gressel \& Segel, 1978; Gressel \& Segel, 1990; Putwain \& Mortimer, 1989; Maxwell et al. 1990; Jasieniuk et al. 1996) teorizam a respeito deste último aspecto, sendo que os principais fatores que o afetam incluem: adaptabilidade ecológica e prolificidade do indivíduo resistente, longevidade e dormên cia das sementes da espécie ou biótipo sob seleção, frequência de utilização de herbicidas de um único mecanismo de ação e sua persistência, eficácia do herbicida e métodos adicionais empregados no controle de plantas daninhas.

O presente trabalho indica que a análise do risco da ocorrência de resistên cia é limitada pela falta de informações genéticas detalhadas nos casos de resistência já constatados até o momento. Os resultados das simulações realizadas indicam que o principal fator que irá de terminar a ocorrência de resistência numa área específica é a freqüência inicial do gene de resistência. As simulações mate máticas suge rem que, em situações de alta infestação de certa espécie daninha, há grande probabilidade de se encontrar um mutante resistente aos herbicidas. Uma interpretação alternativa é: quando a infestação do terreno não for acentuada, mas houver uma grande área infestada com certa espécie vegetal e esta for controlada com produtos que apresentem um único mecanismo de ação, a probabilidade de se en contrar mutante resistente a he rbicida é acentuada. Nessas situações é muito importante se realizar rotação ou misturas de herbicidas de diferentes mecanismos de ação para prevenir a ocorrência de plantas daninhas com resi stência aos herbicidas.

\section{LITERATURA CITADA}

ANÔNIMO. Partnership in the management of resistance. England: HRAC, 1995. 4p.

DARMENCY, H. Genetics of herbicide resistance in weeds and crops. In: POWLES, S. B., HO LT UM, J. A. M. (e ds .) He rb icid e resistance in plants. Boca Raton: Lewis, 1994. Cap. 10. p. 263-298.

GRES SEL, J., SEGEL, L.A. The paucity of genetic adaptative resistance of plants to herbicides: possible biological reas ons and implications. J. Theor. Biol., v.75, p.349-371, 1978.

GRESSEL, J., SEGEL, L.A. Modelling the effectiveness of herbicide rotations and mixtures as strategies to delay of preclude resistance. Weed Technol., v.4, p.186-198, 1990.

HOLT, J. S., POWLES, S. B., HOLTUM, J. A. M. Mechanisms and agronomic aspects of herbicide resistance. Annu. Rev. Plant Ph ysiol. Mol. Biol., v. 44, p. 203-229, 1993.

J ASIENIU K, M., BRULÉ-B ABEL, A.L., MORRISON, I. N. The evolution and genetics of herbicide resistance in weeds. Weed Sci., v.44, p.176-193, 1996.

MACNAIR, M.R., CUMBES, Q.R. The genetic architeture of interspecific variation in Mimulus. Genetics, v. 122, p.211-222, 1989.

Planta Daninha, v. 15, n. 2, 1997. 
MAXWELL, B. D., ROUSH, M. L., RA DOSEVICH, S. R. Pred ic ting the evolution and dynamics of herbicide resistance in weed populations. Weed Technol., v.4, p.2-13, 1990.

MERRELL, D. J. Ecological genetics. Minneapolis: University of Minnesota Press, 1981. 500p.
PUTW AIN, P. D., MORTIMER, A. M. The resistance of weeds to herbicides: rational approaches for containment of a growing problem. Brighton Crop Protection Conference - Weeds. p. 285-294. 1989.

VIDAL, R. A. Herbicidas: mecanismos de ação e resis tência de plantas. Por to Ale gre: Ribas Vidal, 1997. 165p. 